\title{
Daniel Brewer, The Enlightenment past. Reconstructing eighteenth-century French thought
}

\section{Silvia Lorusso}

\section{(2) OpenEdition}

1 Journals

\section{Edizione digitale}

URL: http://journals.openedition.org/studifrancesi/7934

DOI: $10.4000 /$ studifrancesi.7934

ISSN: 2421-5856

\section{Editore}

Rosenberg \& Sellier

\section{Edizione cartacea}

Data di pubblicazione: 1 juillet 2009

Paginazione: 400-401

ISSN: 0039-2944

Notizia bibliografica digitale

Silvia Lorusso, «Daniel Brewer, The Enlightenment past. Reconstructing eighteenth-century French thought», Studi Francesi [Online], 158 (LIII | II) | 2009, online dal 30 novembre 2015, consultato il 13 janvier 2021. URL: http://journals.openedition.org/studifrancesi/7934 ; DOI: https://doi.org/10.4000/ studifrancesi.7934

Questo documento è stato generato automaticamente il 13 janvier 2021.

\section{(c)}

Studi Francesi è distribuita con Licenza Creative Commons Attribuzione - Non commerciale - Non opere derivate 4.0 Internazionale. 


\title{
Daniel Brewer, The Enlightenment past. Reconstructing eighteenth- century French thought
}

\author{
Silvia Lorusso
}

\section{NOTIZIA}

DANIEL BREWER, The Enlightenment past. Reconstructing eighteenth-century French thought, Cambridge, Cambridge University Press, 2008, pp. 260.

1 Rifacendosi alla lezione di Michel Foucault, Daniel Brewer studia le vicende interpretative di tematiche $\mathrm{e}$ autori fondamentali dell'llluminismo francese. Coerentemente al metodo d'indagine, non solo i fenomeni letterari vengono collocati in uno spazio-tempo determinato, ma soprattutto vengono indagate le motivazioni di chi li ha letti e ne ha usufruito. Anzi, proprio la considerazione che non esiste un'interpretazione neutra, ma che il senso di un'opera - e in certi casi anche di un autore o di un'epoca - dipendano sempre dal rapporto che il presente dell'interprete ha interesse ad instaurare col passato dell'interpretato, porta il critico a privilegiare più che l'analisi filologica di alcuni testi illuministi, l'uso che di essi è stato fatto sia nel Settecento stesso, che nell'Ottocento e nel Novecento. Così, ad esempio, il famoso saggio di Cassirer sulla filosofia dei Lumi - decisivo nell'illustrare i rapporti di Kant con la tradizione settecentesca - sarebbe stato dettato dal desiderio di trovare nel Settecento un incoraggiamento al Liberalismo europeo per uscire dagli anni bui del Primo Novecento. Questo approccio foucauldiano che ha conosciuto una speciale fortuna nella cultura anglosassone, mostra nelle analisi di Brewer i suoi pregi e i suoi limiti. Se da una parte, infatti, il critico riesce a ricostruire la vitalità dell'Illuminismo a cui nei secoli successivi varie generazioni sono tornate, spinte da moventi diversi; dall'altra una simile impostazione non sfugge al rischio di annientare i testi a favore della storia delle loro interpretazioni e di non valutare queste ultime sulla base di un criterio di pertinenza e di verità, ma solo sulla base delle loro motivazioni. In tal modo 
da una parte il senso che un'opera aveva per l'autore e per i suoi contemporanei rischia di non avere un primato filologico a cui lo studioso debba attenersi, divenendo soltanto una tappa non particolarmente decisiva della storia del testo; dall'altra un'interpretazione vale quanto un'altra, se a differenziarle non è un criterio di verità, ma solo una diversità ideologica.

2 Brewer prende in considerazione Montesquieu e l'uso che gli Illuministi fecero della sua figura, oltre che dei suoi scritti; Diderot e l'impresa dell'Enciclopedia, concepita non come una sistemazione del reale, ma come una sorta di grande magazzino di informazioni messe a disposizione di tutti, quale presupposto per un nuovo metodo conoscitivo; Rousseau e la lettura della sua opera da parte di Roberspierre; il tema delle rovine come grande ossessione ideologico-estetica di fine Settecento. Il punto di partenza del suo discorso risulta la considerazione della figura di d'Alembert, primo storico della scienza, che rivendica contro le ricostruzioni storiografiche fondate sul principio di autorità uno spazio nuovo per l'intellettuale, basato sulla conoscenza e l'esperienza. Questo spazio di autonomia dello scrittore sarà quello che meglio di ogni altro riuscirà a occupare Voltaire, grazie anche a una indipendenza economica che gli consentiva di prescindere da patronati. Esso, tuttavia, era tutt'altro che facile da conquistare, non solo per l'invadenza dei poteri costituiti, ma anche per la tirannia di un nuovo potere che si affermava a fine secolo, quello del mercato. Particolarmente interessante risulta la parte del saggio dedicata a Diderot e alle straordinarie vicende della sua fortuna critica. Misconosciuto e osteggiato per tutto l'Ottocento che, per altro, come è noto, aveva la possibilità di conoscere solo molto parzialmente la sua opera, veniva finalmente rivalutato in piena Terza Repubblica, grazie all'opera innanzitutto di Lanson. Dunque la sua riabilitazione passava per un regime repubblicano e soprattutto per istituzioni laiche, quali l'Università e la Scuola.

Brewer, insomma, tende a mostrare come le interpretazioni dei grandi autori illuministi, e quindi della Rivoluzione francese, che viene abbastanza regolarmente collegata al loro pensiero, caratterizzano il dibattito otto-novecentesco, secondo uno schema che oppone il progressismo filo-illuminista alla conservazione. Il primo rappresentante di quest'ultima tendenza, la cui opera è illustrata nel saggio, è La Harpe e la sua storia letteraria che canonizza un discredito della letteratura illuminista che durerà grosso modo per oltre un secolo.

4 Il libro di Brewer si presenta documentato, spesso convincente, quasi sempre interessante e di piacevole lettura. Il volume è corredato da una bibliografia aggiornata e da un indice di autori e opere. 